\title{
CANNABINOID RECEPTORS ARE NOT INVOLVED IN ANTINOCICEPTION INDUCED BY SYSTEMIC DICLOFENAC IN MICE
}

\author{
Beiza Chatzisali ${ }^{1}$, Tolga Gaş ${ }^{1}$, Hilmi Kılgın ${ }^{1}$, Kübra Duvan Aydemir ${ }^{2}$, Dilşat Erümit ${ }^{2}$, Ruhan Deniz Topuz ${ }^{2}$, Ahmet
} Ulugöl ${ }^{2}$

\author{
${ }^{1}$ Trakya University School of Medicine, Edirne, TURKEY \\ ${ }^{2}$ Department of Medical Pharmacology, Trakya University School of Medicine, Edirne, TURKEY
}

\begin{abstract}
Aims: It has been long suspected that the cannabinoid system participates in the antinociceptive effects of nonsteroidal anti-inflammatory drugs. We studied the possible effects of cannabinoid receptor antagonism on diclofenac-induced antinociception in the writhing test in mice. Methods: In our study, male BALB/c mice, weighing 20-30 g, were used. Writhing responses were produced by intraperitoneal injection of $0.6 \%$ acetic acid. Different doses of diclofenac (3,10,30 mg/kg, i.p.) were tested, then the influence of AM-251 (1 mg/kg, i.p.), a cannabinoid CB1 receptor antagonist and AM-630 (3 mg/kg, i.p.), a cannabinoid CB2 receptor antagonist on the antinociceptive effects of diclofenac was studied. Results: Diclofenac administration elicited a significant, dose-dependent antinociceptive response; however, neither the cannabinoid CB1 receptor antagonist AM-251 nor the cannabinoid CB2 receptor antagonist AM-630 had any influence on the antinociceptive effect of diclofenac. Conclusion: Iinhibition of cannabinoid receptors does not contribute to the antinociceptive action of systemic diclofenac. Further studies are needed to explain the antinociceptive mechanism of diclofenac. Keywords: AM-251, AM-630, antinociception, cannabinoid receptors, diclofenac
\end{abstract}

\section{INTRODUCTION}

Cannabinoids are a group of chemical compounds, which potentially bind to two recognized cannabinoid receptors (CB1 and $\mathrm{CB} 2)$. They include natural cannabinoids found in synthetic cannabinoids, the cannabis plant and endocannabinoids and constitute a therapeutic alternative for limited indications (1). Dronabinol and nabilone, two synthetic cannabinoids, are approved for chemotherapy-associated emesis; whereas nabilone is also indicated for AIDS-related weight loss (2). In addition, nabiximols ( $\Delta 9$-tetrahydrocannabinol [THC]+cannabidiol) is a plant extract approved for spasticity associated with multiple sclerosis, neuropathic pain and cancer pain (3). Due to their unwanted central side effects, such as the risk of abuse, development of tolerance and physical dependence, etc., cannabinoids are used in the clinics only in the abovementioned indications as alternative agents. Understanding their entire mechanism of action will hopefully enable their use in the aforementioned conditions and new indications.

Nonsteroidal anti-inflammatory drugs (NSAIDs) are the most prescribed medications for treating inflammation, mild to moderate pain, and fever. It is clear that NSAIDs exert most of their effects through inhibition of the activity of cyclooxygenase enzymes (COX-1 and/ or COX-2). On the other hand, unlike classical NSAIDs, paracetamol and dipyrone exhibit analgesic activity probably via their action on the central nervous system. Recent investigations suggest that cannabinoid receptors and augmentation of endocannabinoid activity play important roles in the antinociceptive effects of both paracetamol and dipyrone $(4,5)$. Besides paracetamol and dipyrone, all NSAIDs are expected to increase endocannabinoid tonus both by inhibiting endocannabinoid degradation and by increasing their synthesis via COX inhibition $(6,7)$. Accordingly, it has been proposed that the endocannabinoid system appears to be involved in 
the antinociceptive effect of some NSAIDs, although there are contradictory findings $(6-10,13)$.

Diclofenac is the most COX2 selective of the classical NSAIDs acting by inhibiting COX enzyme and widely used for relieving inflammation, pain and fever. Chronic treatment with THC decreased the analgesic effect of diclofenac, whereas combinations of diclofenac with the fatty acid amide hydrolase (FAAH, primary degradative enzyme for the principal endocannabinoid anandamide [AEA]) inhibitor URB597 showed synergistic interaction $(14,15)$. Here, we investigated whether inhibition of cannabinoid receptors play a key role in the systemic antinociceptive effect of diclofenac.

\section{MATERIAL AND METHODS}

\section{Animals \& ethics}

Experiments were carried out on 2 to 3 month old male BALB/c mice weighing 20-30 g (Center of the Laboratory Animals, Trakya University). There were 12 groups and each group consisted of 6 mice. Mice were maintained under controlled light $(12 / 12 \mathrm{~h}$ day/night cycles) and temperature $\left(21 \pm 2{ }^{\circ} \mathrm{C}\right)$ conditions with food and water ad libitum. Local "Animal Care Ethics Committee" approved this study (Protocol Code: TÜHADYEK-2018/32) and all procedures were conducted according to the guidelines of the Ethical Committee of the International Association for the Study of Pain (IASP) (16).

Study design

The acetic acid writhing test was conducted according to the method described elsewhere (17). Writhing responses were produced by intraperitoneal (i.p.) injection of $0.6 \%$ acetic acid in a volume of $10 \mathrm{ml} / \mathrm{kg}$. Immediately after acetic acid administration, writhing responses were videotaped and scored for $20 \mathrm{~min}$. After testing different doses of diclofenac $(3,10,30 \mathrm{mg} /$ $\mathrm{kg}$, i.p.), the influence of the cannabinoid CB1 receptor antagonist AM-251 (1 mg/kg, i.p.) and the cannabinoid CB2 receptor antagonist AM-630 (3 mg/kg, i.p.) on the antinociceptive effects of diclofenac were investigated. Diclofenac was given 30 minutes before acetic acid injection, and cannabinoid receptor antagonists were administered 10 minutes before diclofenac.

\section{Drugs}

Acetic acid and AM-630 were purchased from Sigma-Aldrich (St Louis, MO, USA) and AM-251 was obtained from Tocris (UK), while diclofenac was diluted from commercial preparations. Acetic acid and diclofenac were dissolved in physiological saline, whereas AM251 and AM-630 were given in 1\% ethanol, 1\% Tween
$80,20 \%$ DMSO and 78\% saline. Doses and treatment times of each drug were selected from previous researches (18-20).

\section{Statistical analysis}

The data were normally distributed. To analyze the antinociceptive effects of diclofenac, the results were evaluated by analysis of variance (ANOVA), followed by Bonferroni post-hoc test. In all statistical analyses, $\mathrm{p}<$ 0.05 was considered significant. The results were presented as mean \pm SEM of six mice per group.

\section{RESULTS}

\section{Antinociceptive effect of diclofenac in the writhing test}

As it was expected, diclofenac $(10,30,100 \mathrm{mg} / \mathrm{kg}) \mathrm{ad}-$ ministration exerted a significant, dose-dependent antinociception in the acetic acid writhing test $\left({ }^{\star} \mathrm{p}<0.05, \dagger\right.$ $\mathrm{p}<0.01, \neq \mathrm{p}<0.0001$, compared to vehicle; Figure 1).

Influence of cannabinoid receptor blockade on diclofenac-induced antinociception

Neither AM-251 (1 mg/kg), a cannabinoid CB1 receptor antagonist nor AM-630 (3 mg/kg), a cannabinoid CB2 receptor antagonist at doses neither elicited any effect on their own nor altered the antinociceptive action of diclofenac when compared with each group other than the vehicle groups $(\dagger \mathrm{p}<0.001, \ddagger \mathrm{p}<0.0001$, compared to vehicle; Figures 2, 3).

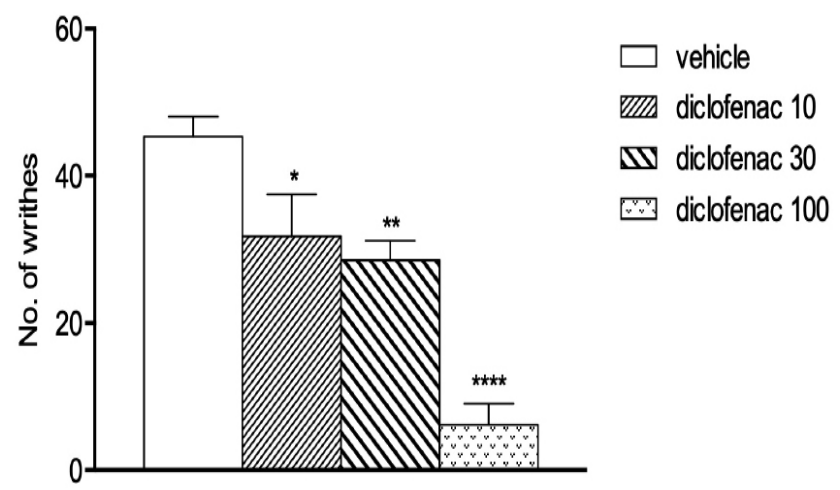

Figure 1: Antinociceptive effect of i.p. injection of diclofenac $(10,30,100 \mathrm{mg} / \mathrm{kg})$ in the acetic acid writhing test $\left({ }^{\star} p<0.05, \dagger p<0.01, \neq p<0.0001\right.$, compared to vehicle). 


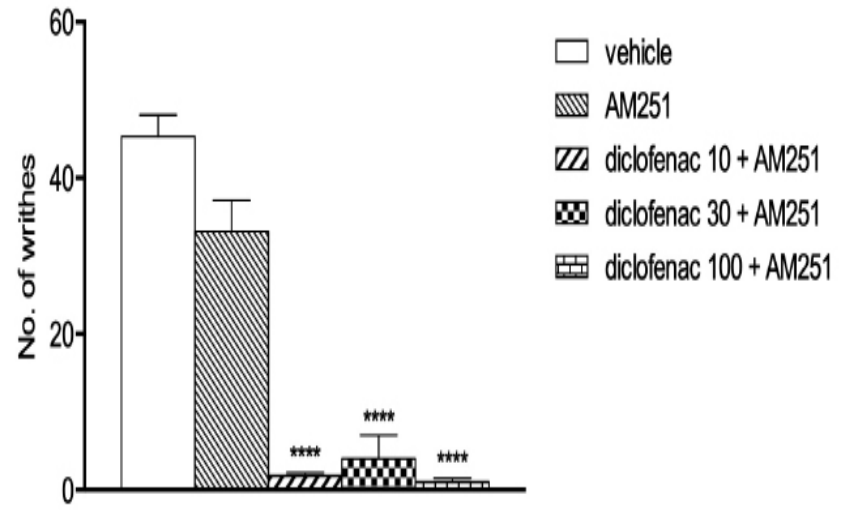

Figure 2: Blockade of antinociceptive effect of systemic administration of diclofenac (10, 30, $100 \mathrm{mg} / \mathrm{kg}$ ) by the cannabinoid CB1 receptor antagonist AM-251 (1 $\mathrm{mg} / \mathrm{kg})$ in the acetic acid writhing test $(\dagger p<0.0001$, compared to vehicle).

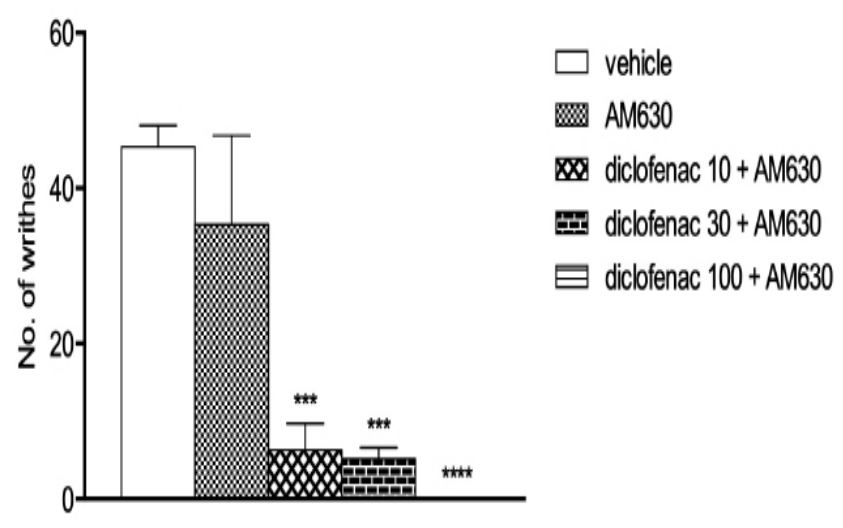

Figure 3: Blockade of antinociceptive effect of systemic administration of diclofenac $(10,30,100 \mathrm{mg} / \mathrm{kg})$ by the cannabinoid CB2 receptor antagonist AM-630 (3 mg/ $\mathrm{kg})$ in the acetic acid writhing test $(\dagger p<0.001, \neq p<$ 0.0001, compared to vehicle).

\section{DISCUSSION}

COX metabolizes arachidonic acid resulting in the synthesis of prostaglandins; there are two isoforms of COX: COX-1 and COX-2 (21). Diclofenac, a classical NSAID, inhibits the enzyme COX and is extensively used for the treatment of mild to moderate inflammation and pain. Here, we investigated whether mechanisms (specifically, cannabinoid receptors) other than COX inhibition play a role in diclofenac antinociception, but our findings indicate that cannabinoid receptors are not involved in the antinociceptive effect of systemic diclofenac.
As we have stated in the introduction, all NSAIDs have the potential of augmenting endocannabinoid levels by inhibiting COX-2 (although with a weak potential) and thereby preventing degradation of endocannabinoids (6, 7,22 ). Inhibition of COX enzymes by NSAIDs may also elevate endocannabinoid synthesis due to the availability of arachidonic acid for endocannabinoid synthesis rather than prostaglandin synthesis $(6,7,22)$. Moreover, some of the classical NSAIDs have been shown to inhibit FAAH directly and reduce the breakdown of endocannabinoids (9). Finally, inhibition of nitric oxide (NO) by NSAIDs may also attenuate the activation of endocannabinoid transporters and thus augment endocannabinoid levels $(6,22)$. In addition to its well-known COX inhibitory activity, this final mechanism can be attributed to the antinociceptive effect of diclofenac, since NO-cGMP-K+ channel pathway has been suggested to be involved in the peripheral antinociceptive effect of diclofenac (23).

Two previous research articles were important in leading us to start this project, but our findings were not as we expected. In one of them, co-administration of diclofenac with the FAAH inhibitor URB597 elicited a synergistic antinociceptive effect (15). In the other, THC given chronically decreased efficacy and potency of diclofenac, but this decrease did not appear to be an endogenous cannabinoid release-mediated; moreover, diclofenac was given per os (p.o.) in this study (14).

Cannabinoid receptors have been suggested not to be involved in the peripheral antinociceptive mechanism of diclofenac following intraplantar administration (24). Here, our experiments extend these findings showing that antagonism of cannabinoid receptors does not influence systemic diclofenac administration-induced antinociceptive activity.

Animal Care Ethics Committee Approval: This study was approved by the Scientific Research Ethics Committee of Trakya University School of Medicine (Protocol Code: TÜHADYEK-2018/32).

Informed Consent: N/A

Conflict of Interest: The authors declared no conflict of interest.

Author contributions: Concept: RDT, AU. Design: BC, TG, HK, KDA, DE, RDT, AU. Supervision: RDT, AU. Resources: RDT, AU. Materials: BC, TG, HK, KDA, DE, RDT, AU. Data collection and/ or processing: BC, TG, HK, KDA, DE, RDT, AU. Analysis and/or Interpretation: $\mathrm{BC}, \mathrm{TG}, \mathrm{HK}, \mathrm{KDA}, \mathrm{DE}, \mathrm{RDT}, \mathrm{AU}$. Literature Search: BC, TG, HK, KDA, DE, RDT, AU. Writing Manuscript: RDT, AU. Critical Review: BC, TG, HK, KDA, DE, RDT, AU.

Financial disclosure: This work was supported by a grant from Trakya University Research Council (TÜBAP-2018/345). 


\section{REFERENCES}

1. Ulugol A. The endocannabinoid system as a potential therapeutic target for pain modulation. Balkan Med J 2014;31:115-20.

2. Schrot RJ, Hubbard JR. Cannabinoids: medical implications. Ann Med 2016;48:128-41.

3. Sastre-Garriga J, Vila C, Clissold S et al. THC and CBD oromucosal spray (Sativex (R)) in the management of spasticity associated with multiple sclerosis. Expert Rev Neurother 2011;11:627-37.

4. Mallet C, Daulhac L, Bonnefont J et al. Endocannabinoid and serotonergic systems are needed for acetaminophen-induced analgesia. Pain 2008;139:190-200.

5. Rogosch T, Sinning C, Podlewski A et al. Novel bioactive metabolites of dipyrone (metamizol). Bioorgan Med Chem 2012;20:101-7.

6. Crunfli F, Vilela FC, Giusti-Paiva A. Cannabinoid CB1 receptors mediate the effects of dipyrone. Clin Exp Pharmacol P 2015;42:24655.

7. Hamza M, Dionne RA. Mechanisms of non-opioid analgesics beyond cyclooxygenase enzyme inhibition. Curr Mol Pharmacol 2009;2:1-14.

8. Paunescu H, Coman OA, Coman L et al. Cannabinoid system and cyclooxygenases inhibitors. J Med Life 2011;4:11-20.

9. Fowler CJ. NSAIDs: endocannabinoid stimulating anti-inflammatory drugs?. Trends Pharmacol Sci 2012;33:468-73.

10. Elmas P, Ulugol A. Involvement of cannabinoid CB1 receptors in the antinociceptive effect of dipyrone. J Neural Transm 2013;120:1533-8.

11. Schlosburg JE, Radanova L, Di Marzo V et al. Evaluation of the endogenous cannabinoid system in mediating the behavioral effects of dipyrone (metamizol) in mice. Behav Pharmacol 2012;23:722-6.

12. Topuz RD, Gunduz O, Karadag HC et al. Endocannabinoid and $\mathrm{N}$-acylethanolamide levels in rat brain and spinal cord following systemic dipyrone and paracetamol administration. Can J Physiol Pharmacol 2019;8:1-7.

13. Saglam G, Gunduz O, Ulugol A. Blockade of cannabinoid CB1 and $\mathrm{CB} 2$ receptors does not prevent the antipruritic effect of systemic paracetamol. Acta Neurol Belg 2014;114:307-9.

14. Anikwue R, Huffman JW, Martin ZL et al. Decrease in efficacy and potency of nonsteroidal anti-inflammatory drugs by chronic delta(9)-tetrahydrocannabinol administration. J Pharmacol Exp Ther 2002;303:340-6.

15. Naidu PS, Booker L, Cravatt BF et al. Synergy between enzyme inhibitors of fatty acid amide hydrolase and cyclooxygenase in visceral nociception. J Pharmacol Exp Ther 2009;329:48-56.

16. Zimmermann M. Ethical guidelines for investigations of experimental pain in conscious animals. Pain 1983;16:109-10.

17. Ulugol A, Ozyigit F, Yesilyurt $\mathrm{O}$ et al. The additive antinociceptive interaction between WIN 55,212-2, a cannabinoid agonist, and ketorolac. Anesth Analg 2006;102:443-7.

18. Gencer A, Gunduz O, Ulugol A. Involvement of descending serotonergic and noradrenergic systems and their spinal receptor subtypes in the antinociceptive effect of dipyrone. Drug Res 2015;65:645-9.
19. Yilmaz I, Ulugol A. The effect of nitric oxide synthase inhibitors on the development of analgesic tolerance to dipyrone in mice. Int J Neurosci 2009;119:755-64.

20. Ertin IH, Gunduz O, Ulugol A. Contribution of nociceptin/orphanin FQ receptors to the anti-nociceptive and hypothermic effects of dipyrone. Acta Neuropsychiatr 2015;27:48-52.

21. Vane J, Botting R. Inflammation and the mechanism of action of antiinflammatory drugs. Faseb Journal 1987;1:89-96.

22. Guhring H, Hamza M, Sergejeva M et al. A role for endocannabinoids in indomethacin-induced spinal antinociception. Eur J Pharmacol 2002;454:153-63.

23. Ortiz MI, Granados-Soto V, Castaneda-Hernandez G. The NO-cGMP-K+ channel pathway participates in the antinociceptive effect of diclofenac, but not of indomethacin. Pharmacol Biochem Behav 2003;76:187-95.

24. Silva LCR, Romero TRL, Guzzo LS et al. Participation of cannabinoid receptors in peripheral nociception induced by some NSAIDs. Braz J Med Biol Res 2012;45:1240-3. 